\title{
Ensinar e aprender língua estrangeira/ adicional na escola: a relação entre perspectivas críticas e uma experiência prática localizada
}

\author{
Teaching and Learning a Foreign/Additional \\ Language at School: Relating Critical \\ Perspectives to a Local Practice
}

Viviane Pires Viana Silvestre*

Universidade Estadual de Goiás

Inhumas - Goiás / Brasil

RESUMO: Este texto reflete sobre a possível reinterpretação de fundamentos globais de perspectivas críticas de ensinar e aprender língua estrangeira/adicional, em um contexto local de escola pública. As ações pedagógicas analisadas foram desenvolvidas nas aulas de inglês de duas turmas de oitavo ano do Ensino Fundamental e fizeram parte das atividades de um subprojeto do Programa Institucional de Bolsas de Iniciação à Docência (Pibid). O estudo aponta para o papel do agenciamento docente, para que expectativas contemporâneas para o ensino de língua estrangeira/adicional (SCHLATTER; GARCEZ, 2012; MONTE MÓR, 2013a, 2013b) sejam vivenciadas no contexto escolar.

PALAVRAS-CHAVE: Língua estrangeira/adicional; Ensino e aprendizagem; Perspectivas críticas; Prática localizada.

ABSTRACT: This paper reflects on the possible reinterpretation of global fundamentals of critical perspectives on teaching and learning a foreign/ additional language in a local public school context. The analyzed pedagogical actions were developed during the English classes of two eighth grade (Junior High School) groups and within the Teaching Iniciation Scholarship Program (Pibid). This study points to the role of the teaching agency in an attempt to allow contemporary expectations for teaching foreign/additional language (SCHLATTER; GARCEZ, 2012; MONTE MÓR, 2013a, 2013b) to be experienced in the school context.

KEYWORDS: Foreign/additional language; Teaching and learning; Critical perspectives; Local practice. 


\title{
1. Introdução
}

\author{
"Espero que algum dia posso ver vocês e que vocês saibam \\ o quanto as aulas de vocês foram importantes pra mim." \\ (Recado deixado por um aluno do $8^{\circ} \mathrm{B}$ no verso da folha \\ do questionário final)
}

A epígrafe que inicia este texto talvez possa parecer deslocada, soando melhor se estivesse ao final. No entanto, decidi trazer a voz desse aluno logo no início porque ela ilustra muito bem o que me motivou a escrever este texto. Nosso mestre Paulo Freire escreveu: "A percepção que o aluno tem de mim não resulta exclusivamente de como atuo, mas também de como o aluno entende como atuo" (FREIRE, 2011, p.95, ênfase adicionada). Ao refletir sobre como alunos e alunas de $8^{\circ}$ ano do Ensino Fundamental de uma escola pública perceberam um conjunto de ações pedagógicas desenvolvidas em suas aulas de inglês, entendi que nossas experiências mereciam ser analisadas e compartilhadas com outras professoras e outros professores de Língua Estrangeira/Adicional ${ }^{1}$ (doravante LE/LA).

Faço parte de um grupo de estudos e pesquisas que busca compreender e vivenciar práticas críticas (PENNYCOOK, 2001) no processo de ensino-aprendizagem de LE/LA, em especial a língua inglesa, por meio da problematização do pensamento hegemônico e de construçōes naturalizadas (PESSOA, 2014). Como pontuado por Pessoa (2014), grande parte dos trabalhos de nosso grupo tem como foco questóes de identidade, raça/ racismo, sexualidade, gênero e classe. No entanto, devido a razões contextuais que mencionarei adiante, o presente trabalho não focaliza nenhuma dessas temáticas e acaba por se diferenciar nesse e em outros aspectos dos estudos comumente realizados pelo grupo, sem, contudo, se afastar da proposta de trabalho crítico.

Ao final de seu texto que traz reflexóes sobre o ensino crítico de LE/LA em um contexto de centro de idiomas, Urzêda-Freitas (2012, p.95) assinala como desafio "investigarmos como essa abordagem [crítica] pode ser implementada no ensino de inglês e espanhol das escolas regulares brasileiras, públicas e privadas". Tendo em vista esse desafio, as ações pedagógicas que serão descritas e analisadas aqui ocorreram no

\footnotetext{
${ }^{1}$ Neste texto, uso os termos "língua estrangeira" e "língua adicional" paralelamente por ter como referencial teórico autores/as que utilizam tanto um como outro termo.
} 
âmbito de um subprojeto Pibid $^{2}$ e foram planejadas e desenvolvidas, colaborativamente, por seis professoras e dois professores, nas aulas de inglês ${ }^{3}$ de duas turmas de $8^{\circ}$ ano do Ensino Fundamental, de uma escola pública de tempo integral do interior de Goiás, nos meses de agosto, setembro e outubro de 2013. Como parte das demandas institucionais, deveríamos seguir o conteúdo previsto no Currículo Referência da Rede Estadual de Educação de Goiás (GOIÁS, 2012) para aquele bimestre, bem como contemplar o livro didático adotado. Tínhamos em nossas mãos a tarefa de conviver com essas demandas sem deixar de lado nosso desejo de realizar um trabalho crítico.

Este trabalho busca respaldo teórico-prático nos estudos sobre prática problematizadora (PENNYCOOK, 2001; 2004; 2012), ensino crítico de LE/LA (PESSOA; URZÊDA-FREITAS, 2012, URZÊDA-FREITAS, 2012, 2013; PESSOA, 2014), letramentos críticos (LUKE; DOOLEY, 2009; KALANTZIS; COPE, 2012; DUBOC, 2012; JORDÃO, 2013a, 2013b; MONTE MÓR, 2013a, 2013b) e educação linguística na formação cidadã (SCHLATTER; GARCEZ, 2012) por acreditar que os (des)encontros desses estudos constituem perspectivas críticas de ensinar e aprender LE/LA. O objetivo deste texto, então, é compreender a reinterpretação de fundamentos globais de perspectivas críticas para as aulas de LE/LA em um contexto local de escola pública. Como aparato metodológico, este estudo utiliza-se do paradigma qualitativointerpretativista (DENZIN; LINCOLN, 2006).

Além desta parte introdutória e das considerações finais, o presente texto conta com três seçôes: na primeira delas, discorro sobre algumas expectativas contemporâneas para o ensino de LE/LA no contexto escolar; em seguida, discuto alguns fundamentos de perspectivas críticas de ensinar e aprender LE/LA; por fim, procuro relacionar os fundamentos teóricos que

\footnotetext{
${ }^{2}$ Programa Institucional de Bolsas de Iniciação à Docência, que objetiva valorizar a formação de professores/as da Educação Básica e oferece bolsas (financiamento CAPES) a alunos/as de licenciaturas que desenvolvem atividades em escolas parceiras, contando com a supervisão de professores/as da escola e a coordenação de um/a professor/a da graduação, que também recebem bolsas.

${ }^{3}$ Participaram desse subprojeto quatro professoras-licenciandas e dois professoreslicenciandos de um curso de Letras Português/Inglês de uma universidade pública, uma professora-supervisora (professora de inglês da escola parceira) e uma professoracoordenadora (professora do referido curso de licenciatura).
} 
foram discutidos a algumas das atividades desenvolvidas no contexto escolar em foco.

\section{O que se espera das aulas de LE/LA na escola?}

Apoiado em Ferreira (2006), Urzêda-Freitas (2013, p.46) alerta que "a escola também é responsável pela construção da cidadania, visto que, nesse espaço, professores/as e alunos/as constroem diariamente suas identidades". No caso das aulas de línguas esse papel é ainda mais evidente, e Moita Lopes (2012, p.10) destaca duas principais razóes: a) "somos seres do discurso que se constroem e se re-constroem pela palavra, que é a matéria principal das aulas de línguas"; e b) "a natureza da sala de aula de línguas, que visa, em última análise, ao exercício da palavra, possibilita que se trate de qualquer tema" - ressalvo apenas que se considerem os fatores contextuais locais.

De modo semelhante, Schlatter e Garcez (2012) compreendem que a escola tem a responsabilidade de oferecer o acesso a LEs/LAs para que os/ as aprendizes possam: conhecer, participar e dar novos contornos à própria realidade; transitar na diversidade; refletir sobre o mundo em que se vive e agir crítica e criativamente. Nesse sentido, a autora e o autor entendem como objetivos do ensino de LEs/LAs, bem como de língua materna e sua literatura, a educação linguística e o desenvolvimento do letramento. Por educação linguística a autora e o autor compreendem "que a escola deve dar 'acesso à escrita e aos discursos que se organizam a partir dela' (Ver: BRITTO, 1997, p.144). E 'dar acesso' quer dizer ensinar a ler com plenitude" (SCHLATTER; GARCEZ, 2012, p.50, ênfase no original). Segundo ambos, isso significa trabalhar textos (orais e escritos) na LE/LA que possibilitem a reflexão sobre questôes significativas para a vida dos alunos e das alunas e que ampliem "o entendimento sobre nós próprios[as] e sobre o mundo em que vivemos" (SCHLATTER; GARCEZ, 2012, p.50). Já o conceito de letramento, a autora e o autor tomam emprestado de Soares (2002, p. $3^{5}$, citado por SCHLATTER; GARCEZ, 2012, p.51), entendendo como "o estado ou condição de quem não só sabe ler e escrever, mas exerce as práticas sociais de leitura e de escrita que circulam na sociedade em que vive, conjugando-as com as práticas sociais de interação oral".

${ }^{4}$ BRITTO, L. P. L. A sombra do caos: ensino de língua x tradição gramatical. Campinas, SP: Mercado de Letras e ALB, 1997.

${ }^{5}$ SOARES, M. Português: uma proposta para o letramento. São Paulo: Moderna, 2002. 
Desse modo, Schlatter e Garcez (2012, p.40) indicam que "a qualidade da educação em línguas adicionais pode significar melhores condições de acesso ao mundo do conhecimento" e, por isso, as aulas de LE/LA devem "ajudar o[a] educando[a] a não virar as costas para os textos do mundo nos quais essa língua se fez e se faz relevante” SCHLATTER; GARCEZ, 2012, p.39). A autora e o autor propõem como justificativa para o ensino de LE/LA na escola, então, a oportunidade de ampliar as possibilidades de participação e ação na vida social e cotidiana dos/as aprendizes.

Os entendimentos de Schlatter e Garcez (2012) acerca do significado das aulas de LE/LA na escola parecem ressoar as seguintes palavras de Jordão (2013a, p.358, ênfase no original):

Ensinar e aprender línguas é, então, ensinar e aprender maneiras de ver, ser, estar e agir no mundo; o papel da escola nesse processo é justamente oportunizar o confronto entre diferentes perspectivas, possibilitar a tomada de decisões "socialmente responsáveis" e ensinar a viver e conviver com a instabilidade e a consequente produtividade que a coexistência de variadas perspectivas instaura em nós.

Depreende-se, então, a evidência do papel político do ensino de LE/ LA na escola regular, fundamentado por questões não apenas linguísticas, mas também culturais, ideológicas e sociais. Confere-se ao estudo da LE/ LA um caráter educativo e crítico, que possibilite ao aluno e à aluna, bem como a seu professor ou à sua professora (re)pensar sobre a diversidade que o/a constitui e que constitui o mundo.

Segundo Monte Mór (2013a), há pelo menos três questões que desafiam as políticas de ensino de línguas na atualidade: 1) falta de agenciamento docente que possibilite reinterpretar as políticas de planejamento globais para seus contextos locais; 2) forte influência de estudos estrangeiros (como bilinguismo, ensino de segunda língua para imigrantes) e, por conseguinte, a carência de políticas de ensino voltadas para os contextos brasileiros; 3) construção da visão hegemônica de que apenas uma parcela da sociedade necessita, de fato, do estudo de LE/LA (língua = capital cultural).

Frente a esses desafios, Monte Mór (2013a) aponta também algumas noções que têm reorientado as políticas de ensino de línguas. Partindo dos estudos de Lo Bianco (2010), Luke et al. (2013) e Pennycook (1994; 2007; 2012), a autora discute o conflituoso encontro de posições universalistas, 
convergentes e hegemônicas que influenciaram e influenciam as políticas de ensino de línguas com posições não convergentes, que valorizam a relação global-local e que têm se fortalecido e reorientado as políticas nacionais de ensino de LE/LA. Essa reorientação ganha força no cenário nacional com a publicação das Orientaçôes Curriculares para o Ensino Médio - Linguas Estrangeiras (BRASIL, 2006), que ressignificam as teorias dos letramentos para o contexto de ensino de LE/LA brasileiro e busca contemplar:

A inserção do ensino de línguas num projeto educacional de escola que desenvolve o conhecimento de idiomas (no caso, de língua inglesa) e, juntamente com esse, volta-se para a formação da cidadania ativa ou engajada; a inclusão social em sentido amplo, não restrita à expectativa, ou a possibilidade de inserção no mercado; a compreensão da relação global-local, na defesa da ideia de que mesmo as orientações em foco necessitariam ser reinterpretadas localmente; a adequação dos propósitos vistos nas políticas de letramentos para o ensino de línguas no Brasil, entendendo a afinidade entre essas áreas no que concerne às visões de língua, linguagem, conhecimento, construção de sentido, sociedade, participação social, relações de poder, dentre outros (MONTE MÓR, 2013a, p.231-232).

A autora destaca, no entanto, que as premissas dessa proposta só podem se tornar reais se houver um investimento no profissionalismo docente para que os professores e as professoras de LE/LA possam ressignificá-las às contingências e peculiaridades locais.

Diante de todas essas expectativas em relação às aulas de LE/LA na escola, evidencia-se a influência de perspectivas críticas de ensinar e aprender línguas, foco da seção seguinte.

\section{Perspectivas críticas de ensinar e aprender LE/LA}

Pennycook $(2001 ; 2010)$ indica uma variedade de domínios da linguística aplicada crítica (doravante LAC), dentre esses o letramento crítico. Luke e Dooley (2009, p.1) definem letramento crítico como "o uso de textos para analisar e transformar relações culturais, sociais e políticas de poder". Segundo o autor e a autora, diferentes versões do letramento crítico têm sido desenvolvidas no contexto de ensino de inglês como segunda língua e LE/LA desde a década de 1980, todas elas fortemente influenciadas pelos trabalhos de Paulo Freire. 
Luke e Dooley (2009) advogam em favor da proposta de pluralização do termo letramento, uma vez que a cultura cibernética, que extrapola a cultura do papel, requer novas formas de ler e de construir sentidos. Além disso, Kalantzis e Cope (2012) afirmam que essa pluralização é mais coerente com as abordagens críticas. Essa autora e esse autor usam o termo pedagogia de letramentos críticos para tratar da questão e apresentam uma lista de palavras-chave que permite compreender melhor essa proposta. Trago, a seguir, um quadro com esses conceitos-chave que, acredito, são essenciais no esclarecimento não apenas da proposta dos letramentos críticos, mas das perspectivas críticas de ensino de línguas em geral.

\section{QUADRO 1}

Conceitos-chave da Pedagogia dos Letramentos Críticos

\begin{tabular}{|c|c|}
\hline Letramentos críticos & $\begin{array}{l}\text { Abordagens para o letramento com foco em textos que comunicam os interesses } \\
\text { e experiências dos/as estudantes e endereçam questôes sociais desafiadoras como } \\
\text { discriminação e desvantagem. }\end{array}$ \\
\hline Pensamento crítico & $\begin{array}{l}\text { Aprender a ver o mundo de múltiplos pontos de vista, não assumindo que as coisas são } \\
\text { exatamente o que os textos dizem ser. Aprender a questionar os textos e interpretar os } \\
\text { interesses humanos expressos neles. }\end{array}$ \\
\hline Discriminação & $\begin{array}{l}\text { Exclusão sistemática de uma pessoa ou grupo de pessoas, baseada em atitudes negativas } \\
\text { em relação a ela(s), e práticas ou hábitos de exclusão. }\end{array}$ \\
\hline Desvantagem & Estruturas sociais que reforçam e reproduzem desigualdade. \\
\hline Identidade & $\begin{array}{l}\text { Maneiras de pensar, se comunicar e ser de uma pessoa baseadas em suas aspirações e } \\
\text { experiências de vida. }\end{array}$ \\
\hline Nova mídia & $\begin{array}{l}\text { Meios de comunicação desde a ascensão da digitalização e da internet, que estão agora } \\
\text { mais acessíveis e que possibilitam uma participação social mais ampla, com mais pessoas } \\
\text { agindo como produtores/as de conteúdos textuais. }\end{array}$ \\
\hline Pós-modernidade & $\begin{array}{l}\text { Uma orientação social baseada na ideia de que não há uma única maneira de ser } \\
\text { humano/a ou uma verdade universal. O que existe é uma ampla gama de perspectivas } \\
\text { baseadas em diferentes experiências de vida, histórias, culturas e interesses. }\end{array}$ \\
\hline Voz & O modo pelo qual uma pessoa expressa suas identidades. \\
\hline
\end{tabular}

Fonte: Adaptado de KALANTZIS e COPE (2012, p.167) ${ }^{6}$

Nota-se, então, que conceitos de identidade, desvantagem, discriminação, pós-modernidade, dentre outros, são basilares da proposta pedagógica dos letramentos críticos. Tal proposta, feita inicialmente para o contexto de ensino-aprendizagem de língua materna, é trazida para o cenário

\footnotetext{
${ }^{6}$ Todas as traduções de trechos originalmente em inglês foram feitas por mim.
} 
de ensino-aprendizagem de LE/LA no Brasil por diversas/os estudiosas/os da área, especialmente as/os participantes do Grupo de Pesquisa do CNPQ, "Novos letramentos, multiletramentos e ensino de línguas estrangeiras", coordenado pela professora Dra. Walkíria Monte Mór e pelo professor Dr. Lynn Mário Menezes de Souza, da Universidade de São Paulo.

Segundo Monte Mór (2013b, p.42), “o[s] letramento[s] crítico[s] parte $[\mathrm{m}]$ da premissa de que a linguagem tem natureza política em função das relaçôes de poder nela presentes", o que implica na inexistência de neutralidade em qualquer texto e requer dos leitores e leitoras uma conscientização crítica para construir seus significados. Nesse sentido, "letramento[s] crítico[s] consiste [m] em não apenas ler, mas ler se lendo" (MENEZES DE SOUZA, 2011, p.296, ênfase no original), ou seja, ter consciência de como se estão construindo os significados. Ainda fazendo uso das palavras de Menezes de Souza (2011, p.297), nessa perspectiva "a metáfora para a leitura é a do dissenso, do conflito. Leitura nunca tem um único significado".

Como coloca Jordão (2013b, p.82-83), nessa visão, ser crítico e desenvolver criticidade requer de nós a percepção de que "nossas próprias crenças e valores também são sócio-historicamente construídos, que nossos próprios textos estão ancorados nos contextos discursivos em que são produzidos". Em outro texto, essa mesma autora (2013a, p.357-358, ênfase no original) argumenta que

nas práticas de letramento que entendem a língua como discurso, não se ensinaaprende um código, mas sim "discursos" ou "palavras-mundo" construídas pelo uso social da língua, um sistema complexo de produção de sentidos que constrói significados em práticas ideológicas. Consequentemente, conhecer aqui é elaborar sentidos, interpretaçōes, perspectivas, relacionando-as umas às outras criticamente, e não apenas codificar e decodificar.

É possível depreender, no trecho acima, como alguns conceitos são entendidos sob a ótica dos letramentos críticos. $\mathrm{Na}$ tentativa de fornecer algumas possibilidades de compreensão dos conceitos de língua, sujeito, conhecimento, aprendizagem e função da educação sob essa perspectiva, construí o quadro a seguir, com base em minha leitura - parcial e conflituosa, como indica Menezes de Souza (2011) - de Jordão (2013b).

\footnotetext{
${ }^{7}$ Link do Diretório de Grupos de Pesquisas do CNPQ http://plsql1.cnpq.br/buscaoperacional/detalhegrupo.jsp?grupo=00678027EO09GQ
} 


\section{QUADRO 2}

Alguns conceitos sob a ótica dos letramentos críticos

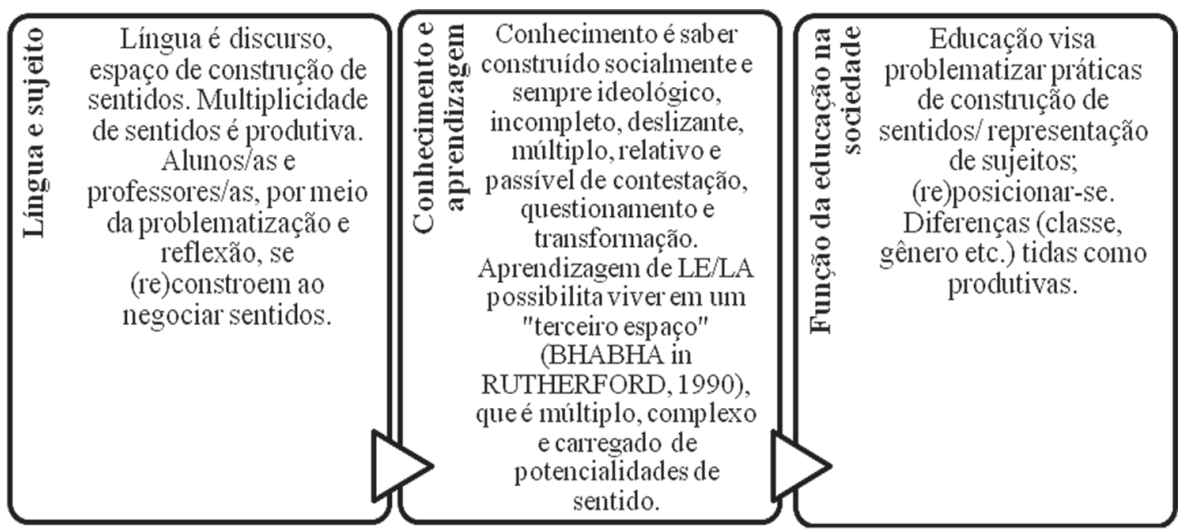

Fonte: Construído a partir de JORDÃO, 2013b.

Nota-se, a partir da leitura dos Quadros 1 e 2 e do exposto nesta seção, que problematizar é inerente às práticas de letramentos críticos. De modo bastante semelhante, Pennycook $(2001 ; 2004 ; 2006)$, ao discutir diferentes acepçóes do termo crítico nos diversos domínios da LAC, advoga em favor de uma prática problematizadora pós-moderna (problematizing practice) que, a seu ver, é: autoquestionadora (consciente de suas próprias limitaçōes); considera a língua como inerentemente política; percebe poder operando nas relações micro e macro; questiona o que é naturalizado (problematiza o que é dado); e se fundamenta em princípios éticos de cuidado com o outro.

Ao tratar especificamente de questôes voltadas para o trabalho crítico nos contextos de educação linguística, Pennycook (2001) alerta que não podemos tratar as salas de aula como lugares neutros, uma vez que tudo que acontece nesse contexto deve ser entendido social e politicamente. Nesse sentido, o desafio colocado pelo autor está em perceber a sala de aula como um microcosmo do mundo social e cultural mais amplo, que não apenas reflete e reproduz esse mundo como também tem potencial de mudá-lo, e, desse modo, suas paredes são permeáveis.

Pennycook $(2004,2012)$ ressalta ainda a importância de estarmos atentos e atentas aos momentos críticos que acontecem na sala de aula (e, eu acrescentaria, em todo ambiente escolar). Por momentos críticos o autor (2004, p.330) entende os eventos inesperados, em que "aproveitamos a oportunidade de fazer algo diferente, quando nos damos conta de que um 
novo conhecimento está surgindo". Nas palavras de Pennycook (2012, p.132, ênfase adicionada), "a educação crítica deve trabalhar com o inesperado tanto quanto com o esperado, uma vez que, se colocamos nossa agenda crítica de antemão, podemos perder justamente esse momentos críticos que importam".

Os conceitos e visões brevemente expostos nesta seção indicam pontos de encontros e desencontros nas diferentes propostas de trabalho crítico. Porém, cabe um questionamento: há uma única e genuina abordagem crítica de ensinar e aprender LE/LA? As leituras que tenho feito e que expus em parte aqui me fazem crer que não. Prefiro compreendê-las como diferentes perspectivas críticas de trabalho no contexto atual de educação linguística. De fato, penso que essa posição plural seja a mais coerente com as premissas da pós-modernidade que tanto influenciam essas propostas.

Nesse sentido, concordo com o desafio proposto por Ellsworth (1989) ao fim de sua acirrada problematização acerca da Pedagogia Crítica: construir práticas pedagógicas que se engajem nos espaços materiais e discursivos do incognoscivel - não há certeza do que pode ser conhecido e deve ser feito $a$ priori-, uma vez que não existe um conhecimento e uma verdade.

Na sequência, apresento algumas atividades desenvolvidas nas aulas de inglês de um contexto escolar público e as analiso à luz dos pressupostos teóricos expostos aqui.

\section{O conhecimento global reinterpretado no contexto local: o que se mostrou possível?}

Grande parte das autoras e autores que discutem as ideias globais das perspectivas críticas de ensino, como as/os citadas/os anteriormente, é unânime em enfatizar a importância de que esses conceitos sejam reconstruídos localmente, considerando os limites e as possibilidades do contexto (alunos e alunas, gestão, infraestrutura, material didático etc.). Como bem coloca Duboc (2012, p.12), "é o contexto local que nos informa constantemente até que ponto pode e quer dialogar com o global”.

Como já mencionado na introdução, o contexto local em foco neste estudo são duas turmas de $8^{\circ}$ ano do Ensino Fundamental de uma escola pública de tempo integral do interior de Goiás (região metropolitana da capital). A carga-horária destinada para a disciplina de língua inglesa era de duas aulas de 45 minutos semanais, que aconteciam às terças-feiras (aulas dobradas) e cada turma contava com uma média de 20 alunos/ as frequentes. Dentre as demandas institucionais, as aulas de LE/LA 
deveriam contemplar tanto o conteúdo expresso no Currículo Referência da Rede Estadual de Educação de Goiás ${ }^{8}$ (GOIÁS, 2012) como o uso do livro didático (uso individual de cada aluno e aluna). Como parte das atividades realizadas nessa escola pelo subprojeto Pibid, que coordenei em 2012-2013, nosso grupo escolheu essas turmas para desenvolvermos uma proposta de ensino colaborativo (MATEUS, 2005) - todos/as do grupo participariam do planejamento, elaboração de materiais e execução de todas as aulas durante os meses de agosto, setembro e outubro de 2013. Essas turmas foram escolhidas por serem consideradas pelo corpo docente as "mais difíceis" da escola, sendo as que mais apresentavam resistências às aulas de inglês. Além da proposta de trabalho colaborativo, nosso grupo já desenvolvia uma proposta de trabalho crítico no formato de oficinas, ${ }^{9}$ fora do horário das aulas da grade curricular, desde o ano anterior na escola. Diante desse novo cenário, tínhamos o desafio de não deixar de lado nossa intenção de desenvolver nossas aulas sob perspectivas críticas.

Tratando especificamente acerca da proposta dos letramentos, Street (2003, p.80) considera que "o resultado do encontro local-global em torno do letramento é sempre uma nova versão híbrida, ao invés de uma única versão essencializada de um dos dois”. Nesse sentido, Duboc (2012, p.56, ênfase no original) argumenta em favor do "ensino de línguas estrangeiras por meio da expansão de perspectivas, numa prática complementar, que não substitui os conteúdos linguístico-culturais do currículo, mas o complementa por meio de uma educação crítica”. Mais adiante, a autora argumenta:

Realizar atitudes pedagógicas sob as premissas do letramento crítico depende, portanto, da atitude docente sobre o currículo. A crítica desejada não se encontra pronta no material didático, no[a] professor[a], nos[as] alunos[a] ou na instituição, mas, sim, na relação que emerge entre todas essas instâncias, cabendo ao[à] professor[a] praticar uma atitude/ postura problematizadora nas brechas de sua prática docente, sempre que as encontrar e julgar relevante (DUBOC, 2012, p.96).

\footnotetext{
${ }^{8}$ Segundo consta no próprio documento, "o Currículo Referência tem como objetivo contribuir com as Unidades Educacionais apresentando propostas de bimestralização dos conteúdos para melhor compreensão dos componentes do currículo e sua utilização na sala de aula" (GOIÁS, 2012, p.8).

${ }^{9}$ Para mais detalhes sobre essa proposta das oficinas temáticas, conferir http://vedipe. blessdesign.com.br/pdf/gt02/co\%20grafica/Viviane\%20Pires\%20Viana\%20Silvestre. PDF. Acesso em: 02 fev. 2014.
} 
Foi justamente essa postura problematizadora que procuramos desenvolver nas brechas que encontramos nos conteúdos e materiais didáticos que tínhamos em mãos. Infelizmente, nossas interações em sala de aula não foram gravadas e por isso não tenho condiçôes de expô-las aqui. Por essa razão, irei me ater à análise das propostas de atividades/discussóes realizadas com as duas turmas.

Em nossa primeira sessão de planejamento para essas aulas, decidimos que iríamos primeiramente atender à proposta curricular indicada para o $3^{\circ}$ bimestre no documento da Secretaria Estadual de Educação (GOIÁS, 2012) para, então, fazer uso do livro didático. Esse documento "tem como finalidade oferecer aos[às] professores[as] elementos para a elaboração de aulas, tendo como meta o trabalho com os gêneros discursivos e as habilidades envolvidas no ensino de Língua Inglesa" (GOIÁS, 2012, p.69). A figura a seguir traz a indicação da proposta para o período em que estaríamos responsáveis pelas aulas de inglês daquelas turmas.

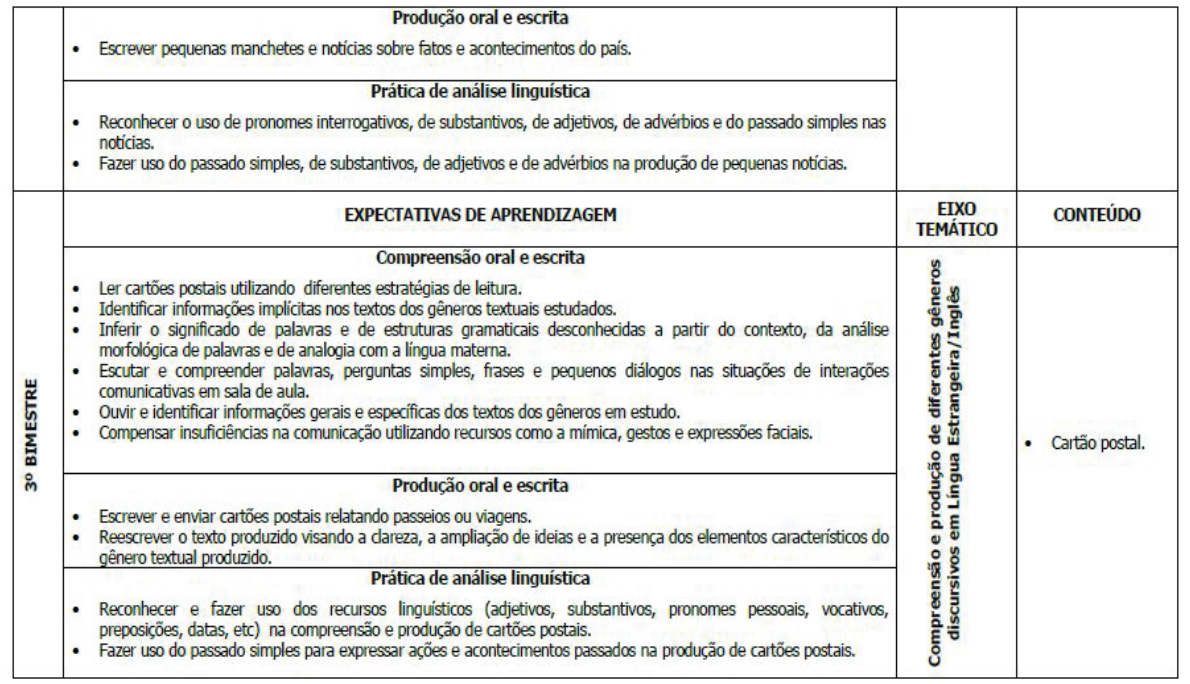

FIGURA 1: Proposta curricular para o $3^{\circ}$ bimestre $-8^{\circ}$ ano do Ensino Fundamental. Fonte: GOIÁS, Currículo Referência da Rede Estadual de Educação de Goiás, 2012, p.77.

Como pode ser notada na figura 1 , a proposta de conteúdo era o trabalho com o gênero "cartão postal". Nosso desafio parecia maior do que esperávamos. Como desenvolver um trabalho crítico com cartões postais? Após muitas reflexões, buscas por materiais na internet e discussões, encontramos algumas brechas (DUBOC, 2012) que julgamos propícias aos nossos objetivos. Listo, a seguir, algumas das atividades desenvolvidas em torno do conteúdo "cartão postal" ao longo de sete aulas: 
1. Apresentação de uma sessão de slides (Prezi), elaborada colaborativamente pelos professores e professoras, com o percurso histórico-cultural das correspondências, passando pela carta de Pero Vaz de Caminha, o surgimento dos primeiros cartôes postais até chegar à atualidade (o texto contemplava as línguas portuguesa e inglesa, intercambiavelmente, a fim de otimizar o tempo dispendido com a atividade). No último slide, havia a seguinte questão: "And you? Do you usually send/receive postcards?", que propiciou uma discussão introdutória sobre o assunto e a problematização desse gênero na contemporaneidade (possível substituição por mensagens de Facebook e Instagram).

2. Busca por pontos da cidade que os alunos e as alunas considerassem passíveis de figurar em um cartão postal. ${ }^{10}$ Eles/as teriam de fotografar o local e enviar as imagens por e-mail a um/a dos/as professores/as ou via Facebook, se preferissem. ${ }^{11}$

3. Elaboração de um cartão postal de uma cidade que conheciam (a imagem foi desenhada e colorida pelos/as próprios/as alunos/as e o texto escrito em inglês).

4. Leitura compartilhada dos postais em sala e exposição dos trabalhos em um evento da escola.

Ao buscar indícios de reinterpretação dos fundamentos globais das perspectivas críticas nas atividades brevemente descritas acima, percebo que conseguimos voltar nosso olhar para as representações e culturas locais (MONTE MÓR, 2013a), especialmente quando consideramos as cidades conhecidas pelos alunos e pelas alunas (a maioria delas, cidades interioranas vizinhas à cidade em que moravam), contrariando uma posição hegemônica que privilegiaria o trabalho com grandes metrópoles e das quais, possivelmente, eles e elas teriam muito pouco a dizer. Além disso, adaptamos aquele currículo de forma a torná-lo "condizente com os[as] estudantes, segundo a bagagem de conhecimentos e culturas que trazem [iam] para a escola" (LUKE et al, 2013, p.29, citado por MONTE MÓR, 2013a, p.229). Além de valorizar o conhecimento e as características locais, creio que possibilitamos também a

\footnotetext{
${ }^{10} \mathrm{Os} /$ As alunos/as fizeram uma busca por bancas de revistas e papelarias da cidade e detectaram que não havia cartóes postais do local.

${ }^{11}$ Poucos/as alunos/as realizaram essa atividade, por isso não houve uma sequência na proposta.
} 
problematização do gênero "cartão postal" na atualidade, promovendo uma (re) construção de sentidos acerca desse gênero discursivo.

Finalizado o trabalho com a proposta curricular do Estado, nossas aulas passaram a ter como ponto de partida o livro didático adotado. Ao analisar as duas unidades que teríamos de trabalhar ao longo dos próximos dois meses, vimos algumas brechas que poderíamos aproveitar para desenvolver um trabalho crítico. Descartamos algumas atividades que julgamos desnecessárias e acrescentamos outras, mais coerentes com nossos objetivos, por meio da expansão de perspectivas (DUBOC, 2012). A figura a seguir traz as indicações de cada unidade.

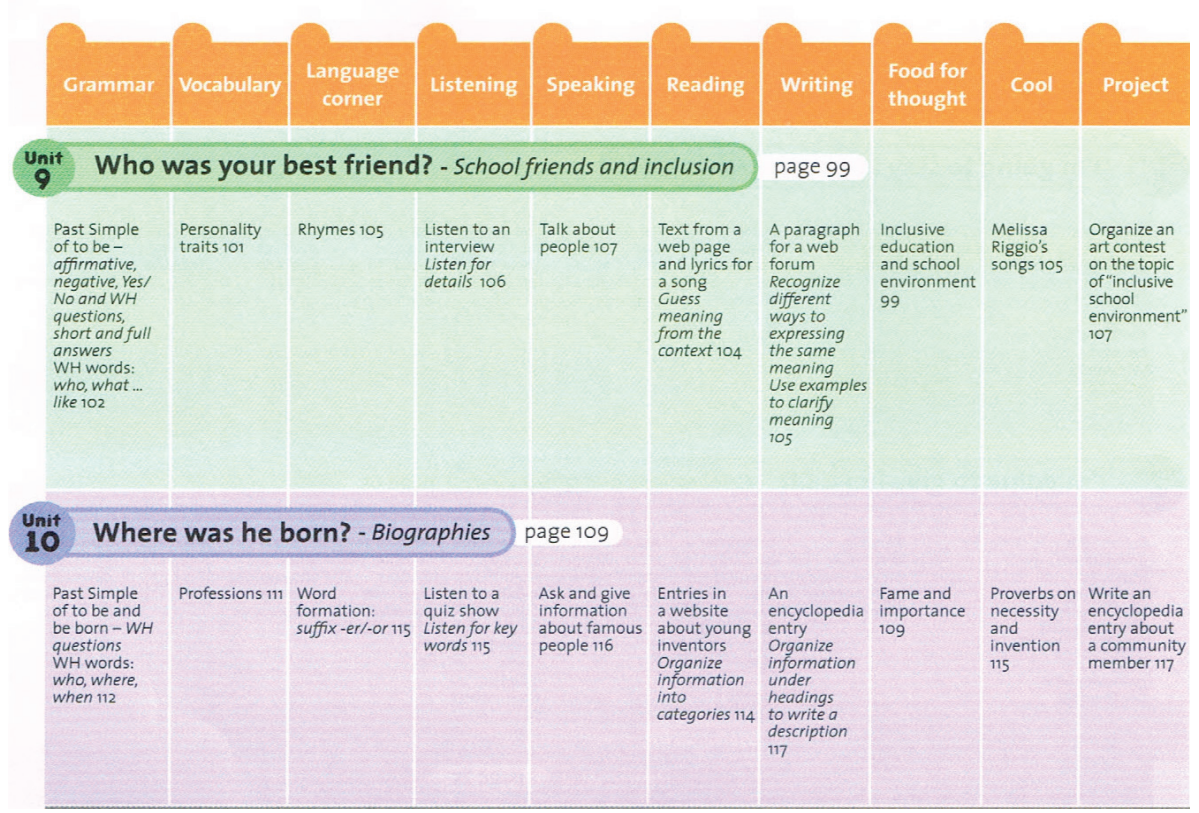

FIGURA 2: Escopo e sequência das unidades do livro didático.

Fonte: CHIN; ZAOROB, 2011, p.6.

A primeira unidade do livro a ser trabalhada por nós tinha como pano de fundo a temática da inclusão e vimos ali uma oportunidade ímpar de problematizar a questão. Fizemos, então, uma inversão de prioridades: evidenciamos a temática e deixamos os conteúdos gramaticais (passado do verbo ser/estar) e de vocabulário (adjetivos descritivos de personalidade) apenas como suporte para a realização das atividades. Na sequência, apresento algumas das atividades desenvolvidas a partir da proposta da 
Unidade 9 do livro didático ${ }^{12}$ ao longo de doze aulas.

1) Discussão do lema "We are all different and we are all the same" (p.99) e sua relação com o vídeo "For the birds"

2) Leitura e discussão de cartazes confeccionados por alunos e alunas de uma escola elementar americana acerca da temática "escolas inclusivas" ${ }^{14}$ (exposição em slides do Prezi organizados pelo grupo de professores e professoras).

3) Proposta de um concurso de artes (Art Contest) entre as alunas e os alunos das duas turmas, contemplando a língua inglesa e a temática da inclusão (adaptação da atividade proposta na p. 107).

4) Trabalho com o filme Como estrelas na terra toda criança é especial, ${ }^{15}$ problematizando as diferenças no contexto escolar (com ênfase no caso da dislexia). O filme foi exposto em sala (com legendas em português) ao longo de três aulas e, nas aulas seguintes, foram feitas discussōes em torno das temáticas abordadas no filme (dislexia, diferenças culturais entre a Índia e o Brasil, tipos de personalidade, papel do/a professor/a, inglês indiano, multilinguismo etc.) e atividades relacionadas ao conteúdo gramatical e de vocabulário.

5) Desenvolvimento das atividades propostas no livro didático sobre os/as portadores/as de Síndrome de Down (p.105).

Todo o trabalho desenvolvido em torno da temática da inclusão teve como premissa a concepção dos letramentos críticos de que as diferenças são produtivas e não focalizamos a anulação dessas diferenças, como comumente se trabalha a temática e, de certa forma, o livro didático propunha. $\mathrm{O}$ foco de nossas atividades estava endereçado a uma questáo social bastante desafiadora, que envolvia discriminação e desvantagem (KALANTZIS; COPE, 2012). Como evidenciam Schlatter e Garcez (2012, p.49), "cabe à

\footnotetext{
${ }^{12}$ As páginas que aparecem na listagem de atividades se referem ao livro didático.

${ }^{13}$ Curta animação da Pixar (3min) que retrata a conflituosa relação igual-diferente. Disponível em: <http://www.youtube.com/watch?v=ltisPppEA3M>. Acesso em: 29 jan. 2014.

${ }^{14}$ Sugestão de atividade extra, proposta no livro didático (p.99). Disponível em: www. nccrest.org/publications/art_products.html. Acesso em: 29 jan. 2014.

${ }^{15}$ Mais informações sobre o filme disponível em: < http://www.taarezameenpar.com/>. Acesso em: 02 fev. 2014.
} 
escola causar o estranhamento e fazer refletir sobre as maneiras como esses valores se materializam no cotidiano e como podemos desnaturalizar o que não mais notamos" e acredito que as atividades e discussões propostas nos fizeram repensar (tanto alunos/as como nós professores/as) e desnaturalizar muitos preconceitos que trazíamos acerca da temática da inclusão escolar. Enfim, lemos nos lendo ((MENEZES DE SOUZA, 2011).

Por outro lado, creio que faltou realizar um trabalho mais diretamente voltado para a inclusão naquele contexto escolar. Em nossas discussões em sala, levantamos essa questão, no entanto, acredito que nosso trabalho teria sido ainda mais relevante socialmente se tivéssemos proposto açôes concretas de mobilização e reflexão que repercutissem em toda a escola. Em reflexões feitas entre nós professoras e professores, consideramos que o trabalho com o filme Como estrelas na terra toda criança é especial poderia ter sido mais bem explorado, uma vez que levamos mais tempo (três aulas) com a exibição do filme do que com as atividades voltadas para ele (quase duas aulas).

Mesmo com essas ressalvas, acredito que, de certo modo, as atividades propostas estavam fundamentadas em princípios éticos de cuidado com o outro, em especial os destacados por J. P. Gee (1993, p.292-293), ${ }^{16}$ citado por Pennycook (2001, p.136, ênfase no original): 1) "que algo que prejudicaria alguém (...) é sempre um bom motivo (apesar de talvez insuficiente) para não fazê-lo"; e 2) "tem-se sempre a obrigação ética de explicar (...) qualquer prática social que, acredita-se, beneficie alguém ou um grupo em detrimento de outras pessoas ou grupos". Afinal de contas, como ensina Freire (2011) e reitera Mochinski (2008), precisamos aprender a ser mais humanos, não menos.

Creio que a imagem de um dos trabalhos vencedores do concurso de artes (Art Contest) que promovemos serve como ilustração das reflexôes que fizemos em sala de aula, exposta na figura 3 .

\footnotetext{
${ }^{16}$ GEE, J.P. Postmodernism and literacies. In: LANKSHEAR, C.; MCLAREN, P. (Ed.). Critical literacy: politics, práxis and the postmodern. Albany, NY: State University of New York Press, 1993, p.271-296.
} 


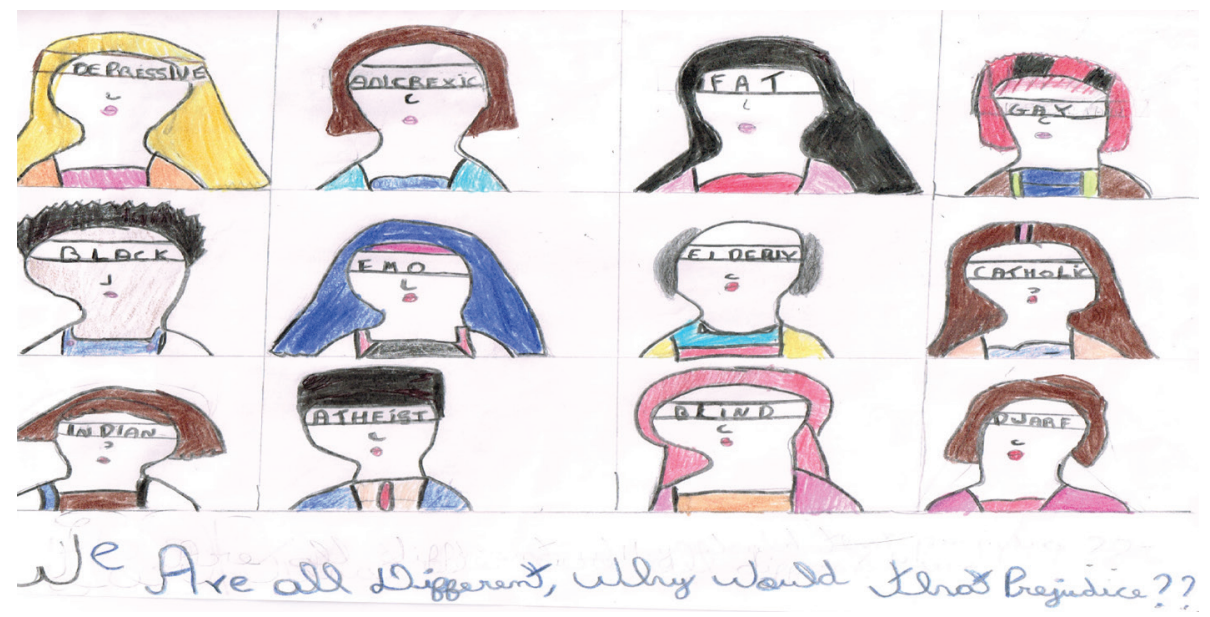

FIGURA 3: Imagem de um dos trabalhos vencedores do concurso de artes (Art Contest)

Vemos, na imagem da figura 3, diferentes tipos de marcas identitárias (depressivo/a, anoréxico/a, obeso/a, homossexual, negro/a, emo, idoso/a, católico/a indígena, ateu/ia, cego/a, anão/ã) e uma questão para refletir: somos todos/as diferentes, por que o preconceito? É fato que nem todos os trabalhos expressaram de maneira tão singular as reflexões que fizemos em sala de aula. É importante destacar também que as atividades suscitaram, em muitos momentos, conflitos culturais (PENNYCOOK, 2001) em que houve a disputa de diferentes visões acerca da temática, o que, acredito, enriqueceu ainda mais nossas aulas e nos permitiu "considerar alternativas para nossas crenças, outras possibilidades para nossas leituras da realidade" (JORDÃO, 2013b, p. 82).

A última etapa de nosso trabalho visava atender à Unidade 10 do livro didático, com foco em biografias de personalidades e o uso de Wh questions (where, when, who) com verbo ser/estar no passado. Ao analisarmos as propostas de atividades do livro didático, verificamos uma demasiada ênfase em escolhas hegemônicas das personalidades e profissões contempladas no material (homens, brancos, profissões de prestígio social), salvo raras exceçôes. Como nos restavam apenas quatro aulas e não concordávamos com essa ênfase dada pelo livro didático, optamos por preparar nosso próprio material, contemplando o conteúdo de maneira um pouco mais contra-hegemônica. Segue a breve descrição das duas principais atividades realizadas: 
1) Apresentação de alguns dados biográficos (em inglês) de mulheres que se destacaram no cenário nacional e internacional, principalmente por lutarem por mudanças de cunho social, por meio de slides (powerpoint) preparados colaborativamente pelos/as professores/as;

2) Atividade de prática oral com as perguntas "quem", "onde" e "quando" para obterem informaçōes sobre data e local de nascimento de algumas pessoas famosas (mas a maioria delas desconhecidas até então pelos/as alunos/as), com características contra-hegemônicas (grande parte delas), por meio de cartôes confeccionados por um dos professores.

Mais uma vez, as propostas de atividade brevemente descritas indicam que fizemos uma expansão de perspectivas (DUBOC, 2012), não deixando a proposta de conteúdo linguístico-cultural de lado, mas, sim, adequando-o a uma proposta um pouco mais crítica, uma vez que abrimos mão de focalizar personalidades com características essencialmente hegemônicas e as substituímos por personalidades com peculiaridades contra-hegemônicas (personagens femininas de diferentes classes, nacionalidades, raças/etnias e profissões). Acredito que as expansões que fizemos contribuíram para que os alunos e as alunas transitassem na diversidade (SCHLATTER; GARCEZ, 2012) muito mais do que o fariam se tivéssemos utilizado exclusivamente a proposta do livro didático.

Trago, a seguir, um quadro com a tentativa de síntese da análise das atividades realizadas, procurando indicar minha compreensão da reinterpretação que fizemos de fundamentos de perspectivas críticas para as aulas de LE/LA no contexto local de escola pública em que atuamos.

\section{QUADRO 3}

Síntese da análise das atividades desenvolvidas

\begin{tabular}{|c|c|c|c|}
\hline Fonte & Conteúdo & Principais atividades propostas & $\begin{array}{l}\text { Indícios de perspec- } \\
\text { tivas críticas }\end{array}$ \\
\hline 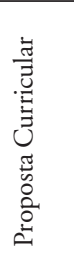 & -Cartão postal & $\begin{array}{l}\text { - Percurso histórico-cultural do gênero "cartão postal"; } \\
\text {-Imagens dos cartões postais da cidade (fotos); } \\
\text { - Produção de cartões postais com foco nas cidades } \\
\text { conhecidas pelos/as alunos/as e leitura compartilhada. }\end{array}$ & $\begin{array}{l}\text {-Estabelecimento da } \\
\text { relação global-local; } \\
\text {-Valorização do co- } \\
\text { nhecimento cultural } \\
\text { dos/as alunos/as; } \\
\text {-Ação pedagógica } \\
\text { contra-hegemônica. }\end{array}$ \\
\hline
\end{tabular}




\begin{tabular}{|c|c|c|c|}
\hline 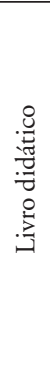 & $\begin{array}{l}\text {-Tema: Inclu- } \\
\text { são } \\
\text { - Ad j e tivo s } \\
\text { (personalida- } \\
\text { des) } \\
\text { - Passado do } \\
\text { verbo ser/estar }\end{array}$ & $\begin{array}{l}\text { - Trabalho com vídeos que suscitaram discussões e } \\
\text { atividades relativas à relação igual-diferente e à temática } \\
\text { da inclusão; } \\
\text {-Concurso de artes (temática da inclusão); } \\
\text {-Leitura e discussão de textos escritos (cartazes feitos } \\
\text { por alunos/as americanos/as e blog de uma portadora de } \\
\text { Síndrome de Down). }\end{array}$ & $\begin{array}{l}\text { - "Diferenças" vistas } \\
\text { como produtivas; } \\
\text {-Princípios éticos de } \\
\text { colocar-se no lugar } \\
\text { do outro; } \\
\text {-(Re)construção e } \\
\text { negociação de sen- } \\
\text { tidos; } \\
\text { - Leitura como dis- } \\
\text { senso. }\end{array}$ \\
\hline 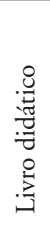 & $\begin{array}{l}\text { - Tema: perso- } \\
\text { nalidades fa- } \\
\text { mosas } \\
\text { - Wh questions } \\
\text { e passado do } \\
\text { verbo ser/estar }\end{array}$ & $\begin{array}{l}\text {-Foco em personalidades com características contra- } \\
\text { hegemônicas; } \\
\text {-Prática oral com informações de personalidades também } \\
\text { com características contra-hegemônicas. }\end{array}$ & $\begin{array}{l}\text { - Reinterpretação de } \\
\text { uma visão universa- } \\
\text { lista e hegemônica } \\
\text { do material didático } \\
\text { para uma visão mais } \\
\text { contra-hegemônica e } \\
\text { desnaturalizada. }\end{array}$ \\
\hline
\end{tabular}

Fonte: Desenvolvido pela autora.

Antes de encerrar, não poderia deixar de mencionar ainda dois aspectos. Um deles é a importância de nossas intervenções "problematizadoras" em vários momentos críticos que aconteceram ao longo dessas aulas. Dado o limite de extensão deste texto, não trarei a discussão desses momentos para o foco; no entanto, comungando da visão de Pennycook (2012), gostaria de enfatizar que são esses momentos inesperados que enriquecem ainda mais nossa tentativa de trabalho crítico. Em sessão reflexiva do grupo Pibid com foco em nossas percepções acerca do trabalho que desenvolvemos nessas turmas, ${ }^{17}$ teço o seguinte comentário:

E outra questão são os momentos críticos, (...) em vários momentos, sim, a perspectiva [crítica] permeou nossa prática. Mesmo que as aulas planejadas não previssem essa perspectiva, (...) nos eventos críticos que surgiam nós tentamos problematizá-los. Eu acho que isso é o mais importante, as coisas que partem sem o nosso preparo, a gente não preparou uma aula para aquilo, aquilo surgir, (...) assim, no discurso deles, alguma coisa que eles falavam, uma atitude com o colega (...)

Outro aspecto importante de ser mencionado é a mudança de atitude dos alunos e das alunas das duas turmas em relação às aulas de inglês. Como mencionado anteriormente, as turmas de oitavo ano foram escolhidas

\footnotetext{
${ }^{17}$ Sessão reflexiva realizada no dia 29/10/2013, gravada em áudio e, posteriormente, transcrita.
} 
por serem consideradas pela professora regente como as que menos se interessavam por suas aulas. No entanto, eles e elas se mostraram muito receptivos e receptivas à nossa proposta de trabalho e se envolveram com as atividades propostas, o que, decisivamente, contribuiu para que seguíssemos com nossos propósitos.

$\mathrm{Na}$ semana seguinte ao término de nossas aulas, retornei às duas turmas para aplicar um questionário aos alunos e às alunas a fim de registrar suas percepções sobre nosso trabalho. ${ }^{18}$ Com exceção de alguns/as que faltaram muitas aulas, todos/as procuraram responder atentamente às perguntas, demonstrando o desejo de expressar o que/como se sentiram naquelas aulas. De modo geral, as respostas indicam que eles/as se interessaram pelas aulas e se envolveram com a proposta de trabalho. Como mencionei logo no início do texto, foi a partir da leitura das respostas desse questionário que decidi propor este texto.

\section{5. Últimas considerações}

Pelo exposto, creio que conseguimos superar ao menos uma das questôes que têm desafiado as políticas de ensino de línguas atualmente, apontadas por Monte Mór (2013a), uma vez que demonstramos nosso agenciamento docente, que nos possibilitou reinterpretar as políticas globais de planejamento para nosso contexto local, convivendo com as demandas institucionais, como o Referencial Curricular e o livro didático. Além disso, acredito que, dentro de nossas possibilidades e limitações, contribuímos para o esperado das aulas de LE/LA na escola: conhecer, participar e dar novos contornos à própria realidade; transitar na diversidade; refletir sobre o mundo em que vivemos e agir crítica e criativamente (SCHLATTER; GARCEZ, 2012).

A análise das atividades propostas às duas turmas de oitavo ano do Ensino Fundamental da escola pública em que desenvolvemos o subprojeto Pibid sugeriu indícios de fundamentos de perspectivas críticas que foram reinterpretadas ao contexto local em foco. Certamente, outros professores e outras professoras poderiam sugerir atividades diversas das apresentadas aqui e que, possivelmente, estariam ainda mais próximas das premissas das perspectivas críticas de ensinar e aprender LE/LA na escola. No entanto,

\footnotetext{
${ }^{18}$ Por limitações de espaço e, de certo modo, por fugir do escopo do objetivo proposto para este texto, não analisarei aqui essas respostas.
} 
minha intenção foi apenas de esboçar o que foi possível fazer naquele contexto e momento, ambos singulares.

Não mudamos a escola, a cidade, nem tampouco nosso país. Nossa prática naquelas turmas de $8^{\circ}$ ano "não suscitou grandes momentos de iluminação, empoderamento ou emancipação, mas foi ao menos inesperada" (PENNYCOOK, 2012, p.148, ênfase adicionada). Aproveitando-me das palavras do aluno que trouxe na epígrafe, espero também um dia vê-lo, bem como seus e suas colegas, daqui a alguns anos e ter a chance de perguntar sobre como foram suas aulas de inglês na escola. Tenho a esperança de ouvir uma resposta diferente da corriqueira: "Só aprendi o verbo to be."

\section{Agradecimentos}

Agradeço imensamente e dedico este trabalho a todos/as participantes do subprojeto Pibid/Letras/Inglês que coordenei em 2012-2013, à equipe gestora e aos/às alunos/as de nossa escola-parceira. Agradeço também à professora Dra. Rosane Rocha Pessoa, aos/às colegas do curso Tópicos avançados na formação crítica de professores/as de LE (UFG/2013) e aos/ às participantes do grupo de estudos Transição pelas valiosas reflexões/ problematizações compartilhadas. Por fim, agradeço à CAPES pelo apoio financeiro no Pibid.

\section{Referências}

BRASIL. Ministério da Educação. Secretaria de Educação Básica. Orientaçōes Curriculares para o Ensino Médio - Linguagens, Códigos e suas Tecnologias. Brasília: MEC/SEB, 2006.

CHIN, E.; ZAOROB, M. L. Keep in mind. $8^{\circ}$ ano. São Paulo: Editora Scipione, 2011.

DENZIN, N. K.; LINCOLN, Y. S. A disciplina e a prática da pesquisa qualitativa. In: DENZIN, N. K.; LINCOLN, Y. S. (Org.). O planejamento da pesquisa qualitativa: teorias e abordagens. Porto Alegre: Artmed, 2006.

DUBOC, A. P. M. Atitude curricular: letramentos críticos nas brechas da formação de professores de inglês. 2012. Tese (Doutorado em Estudos Linguísticos e Literários em Inglês) - Universidade Estadual de São Paulo, São Paulo, 2012.

ELLSWORTH, E. Why doesn't this feel empowering. Working through the repressive myths of critical pedagogy. Harvard Educational Review, v.59, n.3, p.297-324, 1989. 
FERREIRA, A. J. Formação de professores: raça/etnia. Cascavel: Coluna do Saber, 2006.

FREIRE, P. Pedagogia da autonomia: saberes necessários à prática educativa. São Paulo: Paz e Terra, 2011.

GOIÁS. Secretaria de Estado da Educação. Currículo Referência da Rede Estadual de Educação de Goiás. Versão experimental. Goiânia: SEE, 2012.

JORDÃO, C. M. Letramento crítico: complexidade e relativismo em discurso. In: CALVO, L. C. S. et al. (Org.). Reflexōes sobre ensino de linguas e formação de professores no Brasil - Uma homenagem à professora Telma Gimenez. Campinas, SP: Pontes Editores, 2013a. p. 349-369.

JORDÃO, C. M. Abordagem comunicativa, pedagogia crítica e letramento crítico - farinhas do mesmo saco? In: ROCHA, C. H.; MACIEL, R.F. Lingua estrangeira e formação cidadã: por entre discursos e práticas. Campinas, SP: Pontes Editores, 2013b, p. 69-90.

KALANTZIS, M.; COPE, B. Literacies. New York: CUP, 2012.

LO BIANCO, J. Language policy and planning. In: McKAY, N. H. Sociolinguistics and language education. Bristol, Buffalo, Toronto: Multilingual Matters, 2010. p.143-174. LUKE, A.; DOOLEY, K. Critical literacy and second language learning. Forthcoming in E. HINKEL (Ed.). Handbook of Research in Second Language Teaching and Learning (Vol. II). New York: Routledge, 2009. Disponível em:

$<$ http://education.arts.unsw.edu.au/media/File/LukeDooleyCritical_Literacy_in_ SLEDec09.pdf>. Acesso em 29 out. 2013.

LUKE, A. et al. Curriculum, syllabus design and equity. New York and London: Routledge, 2013.

MATEUS, E. Atividade de aprendizagem colaborativa e inovadora de professores: ressignificando as fronteiras dos mundos universidade-escola. 2005. 327f. Tese (Doutorado em Linguística Aplicada e Ensino de Línguas) - Pontifícia Universidade Católica de São Paulo, São Paulo, 2005.

MENEZES DE SOUZA, L. M. T. O professor de inglês e os letramentos no século XXI: métodos ou ética? In: JORDĀO et al. (Org.). Formação "desformatada" práticas com professores de língua inglesa. Campinas, SP: Pontes, 2011. p.279-303.

MOCHINSKI, T. Critical pedagogy: possibilities and limit situations. In: MOCHINSKI, T. Critical pedagogy and the everyday classroom. New York: Springer, 2008. p.1-42. MOITA LOPES, L. P. da. Linguagem e escola na construção de quem somos (Prefácio). In: FERREIRA, A. de J. Identidades sociais de raça, etnia, gênero e sexualidade: práticas pedagógicas em sala de aula de línguas e formação de professores/as. Campinas, SP: Pontes, 2012. p.9-12. 
MONTE MÓR, W. As políticas de ensino de línguas e o projeto de letramentos. In: NICOLAIDES, C. et al. (Org.). Politica e politicas linguisticas. Campinas, SP: Pontes Editores, 2013a, p.219-236.

MONTE MÓR, W. Crítica e letramentos críticos: reflexões preliminares. In: ROCHA, C. H.; MACIEL, R. F. Lingua estrangeira e formação cidadã: por entre discursos e práticas. Campinas, SP: Pontes Editores, 2013b. p.31-50.

PENNYCOOK, A. The cultural politics of English as an International language. United Kingdom: Longman Group Limited, 1994.

PENNYCOOK, A. Critical Applied Linguistics: a critical introduction. New Jersey: Lawrence Erlbaum Associates, 2001.

PENNYCOOK, A. Critical moments in a TESOL praxicum. In: NORTON, B.; TOOHEY, K. (Org.). Critical pedagogies and language learning. Cambridge: CUP, 2004. p.327-345.

PENNYCOOK, A. Uma linguística aplicada transgressiva. In: MOITA LOPES, L. P. (Org.). Por uma linguística aplicada indisciplinar. São Paulo: Parábola, 2006. p.67-84. PENNYCOOK, A. The myth of English as an internacional language. In: MAKONI, S.; PENNYCOOK, A. (Org.). Desinventing and Reconstituting Languages. Clevedon: Multilingual Matters, 2007, p.90-115.

PENNYCOOK, A. Critical and alternative directions in applied linguistics. Australian Review of Applied Linguistics, v.33, n.2, p.16.1-16.16, 2010.

PENNYCOOK, A. Language and mobility. Unexpected places. Bristol: Multilingual Matters, 2012.

PESSOA, R. R. A critical approach to the teaching of English: pedagogical and identity engagement. Revista Brasileira de Linguistica Aplicada, Belo Horizonte, v.14, n.2, p.353-372, 2014.

PESSOA, R. R.; URZÊDA-FREITAS, M. T. Challenges in Critical Language Teaching. Tesol Quartely, v.46, n.4, p.753-776, dez.2012.

RUTHERFORD, J. The Third Space: interview with Homi Bhabha. In: RUTHERFORD, J. (Org.). Identity: community culture difference. London: Lawrence and Wishart, 1990. p.207-221.

SCHLATTER, M.; GARCEZ, P. M. Linguas adicionais na escola: aprendizagens colaborativas em inglês. Erechim: Edelbra, 2012.

STREET, B. What's "new" in New Literacy Studies? Critical approaches to literacy in theory and practice. Current Issues in Comparative Education, Teachers College, Columbia University, Vol. 5(2), 2003. Disponível em:

$<$ http://people.ufpr.br/ - clarissa/pdfs/NewInLiteracy_Street.pdf >. Acesso em: 10 fev. 2014 . 
URZÊDA-FREITAS, M. T. Educando para transgredir: reflexōes sobre o ensino crítico de línguas estrangeiras/inglês. Trabalhos em Linguística Aplicada, Campinas, n. (51.1), p.77-98, jan./jun. 2012.

URZÊDA-FREITAS, M. T. Ensino de línguas como transgressão: corpo, discursos de identidades e mudança social. Jundiaí-SP: Paco, 2013.

Data de submissão: 22/05/2014. Data de aprovação: 06/08/2014. 